\title{
LO QUE LOS AGRICULTORES MÁS REIVINDICAN NO SIEMPRE ES LO QUE MÁS NECESITAN
}

WHAT THE FARMERS MORE CLAIM IS NOT ALWAYS THAT THEY MORE NEED

\author{
POLAN LACKI ${ }^{1 *}$ Ing. Agrónomo. \\ ${ }^{1}$ Ex funcionario $\mathrm{FAO}$
}

\begin{abstract}
"Correspondencia: Polan.Lacki@onda.com.br - Polan.Lacki@uol.com.br
* Información: http://www.polanlacki.com.br
\end{abstract}

Recibido: 06-09-2011, Aceptado: 10-10-2011

Si los agricultores de América Latina me pidiesen sugerencias para resolver sus crónicos problemas les diría algo muy diferente de lo que ellos están acostumbrados a oír. En primer lugar les recomendaría que no sigan esperando que los problemas del agro serán solucionados por sus gobiernos a través de créditos abundantes y baratos, subsidios, reducción de impuestos y peajes, mejor cotización del dólar y garantías oficiales de comercialización de sus cosechas; y les insinuaría que si el crédito rural fuese tan eficaz no tendríamos tantos agricultores tan endeudados. En segundo lugar les sugeriría que consideren como muy remotas las probabilidades de que los gobiernos de los países ricos dejen de subsidiar y proteger a sus agricultores; porque ellos tienen muy poderosas razones internas para seguir haciéndolo. En tercer lugar les mencionaría que estas dos ayudas externas a sus fincas, aunque deseadas, no son tan imprescindibles como los agricultores se las imaginan; pues existe otra ayuda, o mejor dicho una autoayuda, que produce resultados económicos mucho más eficaces con la ventaja de que no son efímeros ni esporádicos sino que son permanentes. Con base en estos tres antecedentes les sugeriría que se vuelvan tan eficientes a punto de no necesitar de las ayudas paternalistas de sus gobiernos y de no verse tan afectados 0 perjudicados por los subsidios y por las medidas proteccionistas vigentes en los países ricos. Este en resumen sería mi mensaje, quizás duro pero realista, a los productores rurales.

Les diría, con honestidad y franqueza, que son los propios productores rurales quienes deberán solucionar sus problemas y que tendrán que hacerlo, corrigiendo 0 eliminando sus propias ineficiencias. Les afirmaría categóricamente que la globalización de los mercados (estemos o no estemos de acuerdo con esta) está imponiendo a nuestros agricultores los siguientes desafíos, reales y concretos: 
a) los productores rurales ineficientes sencillamente no sobrevivirán en la agricultura; y no sobrevivirían aunque les fuesen proporcionadas las dos ayudas externas analizadas en el primer párrafo de este artículo

b) sobrevivirán económicamente apenas los productores rurales muy eficientes. Eficientes en el sentido de que sean capaces de adoptar de manera correcta la mayoría de las siguientes medidas tecnológico-productivas, gerenciales, organizativas y comerciales:

- incrementar los rendimientos por unidad de tierra y de animal para reducir los costos por kilogramo producido;

- diversificar los rubros agrícolas e integrarlos con la producción ganadera para disminuir la excesiva y a veces innecesaria dependencia del crédito rural; y asimismo para evitar riesgos de plagas, de clima e incertidumbres de mercado; el maíz, el sorgo, la soya/soja, la yuca y la alfalfa que los agricultores producen en sus fincas no deberían venderlos al primer intermediario sino que deberían "venderlos" a sus propias vacas, gallinas, pollos y cerdos, con el fin de reducir los costos de las raciones balanceadas;

- hacer la reconversión productiva para reemplazar cultivos menos rentables por otros más rentables (diferenciados, más sofisticados o de mayor densidad económica); en el mundo globalizado y altamente competitivo es difícil que un agricultor, produciendo en pequeña escala, pueda sobrevivir económicamente cultivando yuca, algodón, maíz, frijol, arroz o papas; máxime si los vende tal como los cosechó (sin añadir valor) y si lo hace al primer intermediario que le compra directamente en su finca;

- mejorar la calidad de los bienes producidos y, siempre que sea posible, someterlos a un mínimo procesamiento inicial (limpieza, clasificación, secado/deshidratado, fraccionamiento, etc.) a efectos de obtener mejores precios en la comercialización y, finalmente, lo más imprescindible;

- organizarse con sus vecinos para realizar en conjunto y con menor intermediación la adquisición de los insumos, la comercialización de las cosechas y la realización de aquellas inversiones que, debido a su alto costo y baja frecuencia de uso, económicamente no se justifiquen hacerlas en forma individual.

Sin embargo, en la actualidad muchos agricultores, aunque quisiesen, no podrían adoptar estas medidas "eficientizadoras" de su negocio agrícola porque no han sido formados ni capacitados para que sepan y puedan hacerlo. Por esta razón los productores rurales deberán abandonar las ingenuas utopías paternalistas en espera de humillantes migajas gubernamentales; y, en 
reemplazo, deberán adoptar una actitud más constructiva de organizarse para exigir y participar activamente en la puesta en marcha de algunas medidas más concretas, eficaces y definitivas para emanciparlos de las dependencias y vulnerabilidades a las cuales están sometidos en la actualidad. Entre otras, las descritas a continuación.

1) La agricultura latinoamericana necesita contar, con carácter de urgencia, con un nuevo y muy eficiente servicio de asistencia técnica y/o extensión ruralSATER. Eficiente en el sentido de que tenga real capacidad de enseñarles a los agricultores, especialmente a los pequeños y pobres que constituyen la gran mayoría, algo tan elemental como lo siguiente: qué y cómo deberán y podrán hacer para que puedan solucionar sus problemas de manera más autónoma y autogestionaria. Es decir, que puedan resolverlos sin depender de las cada vez más improbables ayudas de sus empobrecidos, burocratizados e inoperantes gobiernos. Para que esta autonomía/emancipación sea posible, los extensionistas deberán estar capacitados para enseñarles, en primer lugar, a identificar y a utilizar plena y racionalmente los recursos que los productores rurales ya poseen y a aplicar de manera correcta tecnologías de bajo costo para que sean compatibles con dichos recursos. De poco servirá que sigan difundiendo "recetas" sofisticadas si los productores no disponen de los "ingredientes" necesarios para adoptarlas. Este renovado SATER deberá ser cofinanciado por el Estado y por los distintos integrantes de las cadenas productivas; y su administración deberá estar a cargo de una organización privada y sin fines de lucro, perteneciente a los propios integrantes de las mencionadas cadenas. Deberá ser privado y "despolitizado" para que esté inmune a los cambios de gobiernos y a las perniciosas interferencias políticopartidarias en la designación de sus autoridades y en la ejecución de sus programas. Este es el perfil del SATER que está necesitando la gran mayoría de los agricultores: sencillo, ágil, desburocratizado, despolitizado, descentralizado y, sobretodo, eficaz en la solución de los problemas concretos y cotidianos de los productores rurales. Sin embargo, para que dicho servicio sea eficaz será necesario...

2) Capacitar a los miles de profesionales y técnicos en ciencias agrarias, que están desempleados o trabajando pero con bajísima eficiencia y productividad, porque no poseen los conocimientos ni las habilidades necesarias para corregir los errores más frecuentes que la mayoría de los agricultores está cometiendo. Es inaceptable que tengamos tantos extensionistas desempleados 0 improductivos mientras los productores rurales fracasan económicamente, exacta y coincidentemente, porque les faltan los conocimientos agronómicos, zootécnicos y veterinarios que dichos profesionales y técnicos deberían proporcionarles. Esta incoherencia puede ser contrarrestada, con carácter de emergencia y de manera muy sencilla, ofreciéndoles una capacitación eminentemente práctica, a fin de que dominen las técnicas de producción, 
administración rural y comercialización; y asimismo los métodos y medios de extensión rural para que sepan difundir sus recomendaciones a los agricultores y lograr que ellos las adopten de manera correcta. Los capacitadores de estos extensionistas deberán partir de la premisa de que la gran mayoría de los productores rurales de América Latina disponen de recursos financieros muy limitados para adquirir insumos de alto costo y para realizar inversiones. Debido a estas restricciones, la capacitación deberá ser gradual o paulatina, empezando por aquellas medidas correctivas (tecnológicas, gerenciales y comerciales) de bajo costo y mínima dependencia de ayudas externas a sus fincas. A través de cursos intensivos de 2 o 3 meses de duración, eminentemente prácticos, realizados directamente en las fincas, comunidades y mercados rurales y adoptando el método de enseñar y aprender haciendo, será posible transformar a profesionales desempleados e improductivos en extensionistas eficientes y altamente productivos. Después que los agentes de extensión rural reciban esta capacitación gradual, sus recomendaciones iniciales serán tan sencillas y de tan bajo costo, que podrán ser adoptadas por todos los agricultores; por más escasos que aparentemente sean sus recursos productivos. Estos extensionistas debidamente "renovados" y "energizados" difícilmente seguirán desempleados porque encontrarán muchos empleadores ávidos de contratar sus servicios de asesoramiento técnico. Sin embargo, no es lógico que el SATER sea obligado a contrarrestar, año tras año, las ineficiencias de formación de las facultades de ciencias agrarias, teniendo que capacitar a los profesionales ya egresados en conocimientos y habilidades que ellos deberían haber adquirido mientras estaban realizando sus estudios universitarios. Esta distorsión podrá ser corregida a través de la medida sugerida a continuación.

3) Gran parte del pragmatismo propuesto para la capacitación de los extensionistas ya graduados, también deberá imperar en la formación de los actuales estudiantes de las facultades de ciencias agrarias, porque muchas de ellas están formando profesionales tan teóricos que, reconocida y categóricamente, están siendo rechazados por el mercado laboral. Las mencionadas facultades no pueden ignorar que las oportunidades de empleo en los organismos públicos/estatales son cada vez más limitadas. Asimismo ellas deben reconocer que el gran desempleo de sus egresados se debe muchísimo más a la oferta inadecuada de esas instituciones educativas que a la demanda insuficiente del mercado trabajo. Por esta razón deben formar egresados con un perfil más creativo/ingenioso, ejecutivo, pragmático y emprendedor porque son estas las "cualidades" que el gran mercado laboral privado desea encontrar en los extensionistas. Para formarlos con este perfil, dichas facultades deberán "desurbanizarse" y ofrecer una enseñanza más práctica y con mayor vivencia de la problemática agrícola, que sea realizada mucho más en las fincas, comunidades y mercados rurales que en las aulas, computadoras y laboratorios urbanos. Ellas deben adoptar el método de 
"enseñar y aprender haciendo" a efectos de estimular la creatividad y el ingenio tan necesarios a los ingenieros y también a efectos de desarrollar sus habilidades manuales requeridas para la eficiente ejecución (y demostración a los agricultores) de las prácticas agronómicas, zootécnicas y veterinarias. Sin embargo, de poco servirá formar y capacitar a excelentes extensionistas si sus futuros clientes/usuarios/beneficiarios (los alumnos de las escuelas fundamentales rurales) siguen recibiendo una educación de mala calidad y con contenidos curriculares inadecuados a las necesidades imperantes en la agricultura y en las comunidades rurales. El proceso de enseñanza-aprendizaje será realmente eficaz y productivo cuando los extensionistas sepan enseñar y los agricultores sepan aprender. Lo anterior requiere la adopción de la medida descrita en el próximo ítem.

4) Efectuar una profunda modificación en los contenidos curriculares de las escuelas fundamentales rurales. $\mathrm{Si}$ ellas son rurales deberán "agriculturalizarse" y "ruralizarse". Se recomienda extirpar de sus programas la enseñanza memorística de los contenidos de escasa o nula relevancia para las necesidades de vida y de trabajo imperantes en el campo, como por ejemplo: la historia del Imperio Romano y Bizantino, la historia de Luís XIV, Luís XV y Luís $\mathrm{XVI}$, los faraones y pirámides de Egipto, los Jardines Colgantes de Babilonia, la historia de la Mesopotámica, las guerras de Napoleón y de otros "héroes" de países lejanos, las altitudes del Everest y de las Montañas Rocosas de los EUA, el largo del Río Nilo, etc. En vez de enseñar sobre el Río Nilo esas escuelas deberán enseñarles cómo proteger las nacientes/vertientes y no contaminar el río de su comunidad. En vez de enseñar sobre los Jardines de la Babilonia deberán enseñarles cómo instalar huertas caseras y plantar árboles frutales en las fincas para mejorar la ingesta de vitaminas y sales minerales de sus familias. En vez de enseñarles sobre los "héroes" que promovieron guerras en países lejanos deberán enseñar a los niños la historia de los héroes de sus comunidades y municipios que han sido productores muy eficientes, buenos padres y madres de familia que han otorgando una educación ejemplar a sus hijos, que han sido solidarios con sus vecinos y han contribuido al desarrollo de su comunidad, etc. Las escuelas fundamentales rurales deberán incluir en sus currículos contenidos utilizables por los futuros agricultores y sus familias, como por ejemplo: conceptos y nociones básicas sobre producción agrícola diversificada y eficiente, administración rural, prevención contra pérdidas poscosecha, incorporación de valor agregado utilizando la mano de obra familiar, comercialización, organización de las comunidades para solucionar problemas de interés común, educación familiar, educación alimenticia, higiene, prevención de enfermedades y cuidados con la salud, producción y uso de plantas medicinales, primeros auxilios en caso de intoxicaciones con pesticidas, picaduras de serpientes y otros accidentes rurales, etc. Asimismo deberán formarlos para que adquieran valores de aplicación permanente y universal, como honestidad, disciplina, puntualidad, responsabilidad, deseo de 
superación y ambición sana para triunfar en la vida a través del trabajo honesto y bien ejecutado, solidariedad, asociativismo, cumplimiento de sus deberes como miembros de la familia y de la comunidad, respeto por los derechos de los demás, la práctica del ahorro, de la inversión y de la previsión para la vejez, etc. Gran parte de sus actividades educativas/formativas deberá ser realizada fuera de las aulas, para que los niños vean/apliquen/ejecuten en la práctica los conocimientos teóricos recién adquiridos y para que conozcan experiencias positivas adoptadas por familias, fincas y comunidades que puedan servir de buenos ejemplos a ser seguidos por todos los alumnos. Dichas escuelas deberán advertirles sobre los riesgos y peligros de las drogas, del alcoholismo, de la violencia, de la delincuencia, de las prácticas sexuales imprudentes e irresponsables, etc. Asimismo deberán ofrecer una educación que eleve el ego, la auto confianza y la autoestima de los futuros agricultores, al demostrarles que ellos son muy importantes para el desarrollo económico y social del país; y que las actividades agrícolas y ganaderas ofrecen reales oportunidades de prosperidad económica y de realización personal para quienes trabajan con dedicación, eficiencia, honestidad, cooperación y profesionalismo.

5) Capacitar y adecuar la formación de los maestros rurales. La reformulación de los contenidos curriculares y de los métodos pedagógicos de las escuelas fundamentales rurales exige que los actuales maestros rurales también sean capacitados y que las facultades de educación/pedagogía formen los futuros maestros rurales con conocimientos y vivencias de la realidad agrícola y rural. Si esto no ocurre ellos no sabrán qué y cómo deberán enseñar a los niños del campo, de modo que ellos sean productores más eficientes y mejores ciudadanos rurales. En otras palabras, es recomendable adoptar con los maestros de las escuelas fundamentales rurales, actuales y futuros, medidas de capacitación y formación similares a las que, en los ítems 2 y 3 de este artículo, se propuso adoptar para los extensionistas agrícolas.

En resumen, niños bien formados por los maestros de las escuelas fundamentales rurales y agricultores bien capacitados por los extensionistas de un servicio de extensión rural realmente eficiente estarán en condiciones de corregir las principales ineficiencias de los productores rurales y sus familias. Después que lo hagan, ellos mismos serán quienes solucionarán sus problemas; y gracias a esta medida liberadora, el retórico paternalismo estatal será sencillamente prescindible y hasta innecesario. 